\title{
Information Standards enabling or constraining Innovative Hospital Facilities? -A Scandinavian case
}

\author{
Christian Koch ${ }^{1}$, Kim Jacobsen ${ }^{2}$ and Anita Moum ${ }^{3}$ \\ ${ }^{1}$ Chalmers university of Technology \\ ${ }^{2}$ K-Jakobsen A/S \\ ${ }^{3}$ Norwegian Institute of Science and Technology
}

\begin{abstract}
The losses from suboptimal interoperability in IT supported design, production, and operation of health care facilities are tantamount. In these years new built of hospitals in Scandinavia could be realized in a more efficient and innovative way if using information standards. This paper inquires into whether computerized information standards enable or constrain innovation in public procurement of buildings. In architectural and engineering design of public buildings the project based product development tends be done in constellations of firms in interorganisational contracting, which do not provide stability or room for innovation. A large hospital project was investigated through interviews, documents and observations. The effects of implementing building information standards are both inter- and intraorganisational. The building client claims to have saved money, through better structured building component data that gave considerable positive effects during tendering. The IT-suppliers develop IT-tools, and the AEC companies can commence develop services preparing for new markets.
\end{abstract}

Keywords: information standards, innovation, hospital buildings, Denmark, Norway, Sweden

\section{Introduction}

The healthcare sector represents an important part of the Scandinavian welfare states [1] and these countries invest the most in Europe [2]. And in these years we witness an unprecedented wave of investment in renewal and extension of this infrastructure. Norway thus invested an estimated 10 billion Euro in new hospitals from 2000 to 2011 [3], and Denmark has announced future investment at 5, 5 billion Euro[4]. Sweden as well invests in large projects in its major cities and generally [2]. 
A part of this development is the emergence of large business suppliers of services for building and operating these hospital services in architectural, engineering, contracting and real estate industries [5]. Companies like Arkitema (architects), Bravida (technical installations), C.F. Møller (architects), Cowi (engineers), Skanska (contractors) and Veidekke (contractor) all contribute to the renewal of the Scandinavian hospitals and do it in a multinational manner across the Scandinavian countries and beyond. These companies appear well placed to participate in further development of healthcare sectors in for example US, and BRIC-countries.

However in order to exploit these business opportunities Scandinavian architects, consulting engineers, contractors (AEC) and real estate firms need to tackle the issue of lack of proper interoperability of building information, which continues to be a major challenge not only for hospital projects but for the building industry as such [6, 7]. As the information get incorporated in Building Information Models (BIM) and when these complex combined 3D geometric, and multidimensional datamodels become used in design, production and operations processes of the large complex hospital buildings as central design- and support tool, a swift, efficient and smoothless transfer between different parts of the process is crucial $[8,9]$. Moreover an standardized internal structure of data in building information models not only enable transfer/interoperability but also help using BIM in a strategy for creating innovative solutions for new sustainable energy efficient buildings and to enable competitive innovations for Scandinavian building companies, enabling their prospering both locally and globally.

There is thus a need for common tools, standards and work methods. Design production and use of state-of-the-art sustainable building norms similarly requires a set of calculation, design and monitoring tools, which today remains national in their character in contrast to the demands of the market. At present international standards such as Eurocodes and Industry Foundation Classes (IFC) [10] and defacto standards such as DWG only partially cover the Scandinavian building processes, even if IFC is gradually developing as a global standard.

One nationally embedded, but new, standardisation tool is the Cuneco Classification System (CCS) [11]. This clustered set of building information standards is developed in a Danish context, but designed to be used in international building sectors. The standardisation of CCS target building information as used in design, building and operation of buildings. CCS provide a classification of rooms as basic elements of the building product, automated identification and classification of building components, building sub systems, properties of building component, classification of resources for the building process and a standard for information level supporting the building process. A central element is a cloudbased server for access to the standards and the standards are currently built into a small group of software vendor's product. The computerized CCS enables smoothless data transfer between software packages which today are often not interoperable, be it software for engineering design of heating- ventilation- and air condition (HVAC) and energy calculation- software, when combining sustainable design and indoor climate design. Also CCS would, through more integrated IT infrastructures, enable virtual collaboration and coordination which gain importance in and outside the 
Scandinavian region. CCS would thereby systematically overcome obstacles for innovation in building design, production and operation. Yet and importantly it has still not been tested outside Denmark and it is more than likely that its international diffusion will be complete dependable of design of engines and interfaces that can translate from one standard to another in a future multi standard landscape, such as it is known in other areas of standardisations $[12,13]$.

The aim of this contribution is to investigate whether computerized information standards using CCS as case enable or constrain innovation of hospital buildings and investigate under what circumstances information standards would have an improved impact on innovation.

The two main elements of this investigation are a preliminary literature review and a case of a Danish hospital testing the concrete set of standards, i. e. CCS [14].The standards are presently released in their first operable version. Other parts of the backup structures are still under final development. The classification is expected be fully avaible for use by the end of 2014 [11].

In the context of hospital building, the public authorities have often been change agents using procurement to generate standardisation and innovation. Recently EU has pointed to the public authorities as spearhead for energy efficient buildings mitigating climate change [15]. Public procurement of hospital buildings involves demands of use of IT, collaboration and quality tools. This context is therefore particularly interesting for studying links between standards and innovation.

A literature review is used to develop five types of impacts that standards can have on innovation. This is thus the papers primary contribution to analyse how the envisaged standardisation with CCS enables innovation in procurement of hospitals and in building in general. The five types of impact is investigated in the case and the effects presented. However also the barriers for obtaining these results of improved innovation are identified. The paper is structured in the following way. After a method presentation, a selective literature review is used to develop the five types of innovation enhancing effects of standardisation. Using this framework structures the presentation of the Danish Hospital case, which is analyzed in the discussion arriving at the conclusion.

\section{Method}

The scientific approach taken here for business informatics research is critical interpretivist [16, 17] adopting a sociomaterial view on innovations and standards [18]. This approach emphasizes the inseparability of the social and technical aspect as well as both aspects negotiated interpreted character. The results presented here are preliminary as the research project behind is ongoing. The method consists of two main elements, a literature review and a case study, followed by a qualitative analysis:

The literature review is carried out covering Science Technology and Society studies, innovation studies, information systems, Human Computer Interaction and organisation theory approaches $[17,19]$. To do this several search engines was used, 
including ABI/Inform and Scopus. Main search item was "standards AND innovation". Through several rounds of iteration this gave a focus set of roughly 50 articles. Also backtracking and an element of serependity were involved [20] when combining searches in several communities. Currently 55 articles and books are under review, and 31 have been used for this paper, a selection based on the preliminary reading of the abstracts of the articles and introduction of the books. The review leads to a framework of understanding of the relation between computer based standardized information and five types of innovation.

The selected domain for the case study of effects of standards on innovation is architectural and engineering design, production and operation of hospital buildings. Here handling of information gives rise to substantial interoperability issues that tends to hamper innovation. Moreover the project based production of products in the building sector tends be done in constellations of firms in inter organisational contracting, which do not provide stability or room for innovation. The Architecture, Engineering and Construction industry is therefore often portrayed as lagging behind regarding innovation. Here a hospital project with its size in resources and time potentially provide an exemption that could foster innovation. As empirical "test" field a large Danish hospital project is used, which is the building project in Denmark which have used the CCS standards most extensively. It is therefore a critical case and not intended to be typical. The material gathered for this case is composite. First the second author took part in a test project, where building consultants, IT vendors and the client participated and the author could carry out observations through presence at 40 meetings with the design team, the steering group, the IT-supplier's groups and other events. He also carried out a series of interviews, typically of the duration of one hour with these actors in the test project. Second, and supplementary, the first author acts as process evaluator for "Knowledge Center for increased Productivity and Digitalization in Construction" (Cuneco) [11], together with two colleagues from 2010-2015. The process evaluation of the center encompasses by February 2014, seven short half-year process evaluation reports. As the entire center focuses on establishing an building information standardization, most of the material gathered is relevant as background material to the research questions raised here. Data collection encompasses interviews (42), participant observation of events (17), document analysis (141). However more specifically a representative of the hospital test project was interviewed four times during 2012 and 2013. And the document analysis of the developed standards contributed to the understanding of the innovation opportunities. The third author has an independent position vis a vis the Danish classification effort.

The case material is analysed with the framework developed by the literature review. Some of the dimensions turn out to have more weight than others, and it is therefore not strived at to give the dimensions equal emphasis. The analysis is moreover qualitative even if a few figures do occur. Finally the analysis carried out here builds on $[21,22]$. 
Information Standards enabling or constraining Innovative Hospital Facilities? -A

Scandinavian case

The limitations of the study are that the case of classification studied is not a long term stabilised one, but was rather prototypes under development. Many of the more indirect innovation types relating to business models and community [23] is more of a future potential for the time being. Moreover two authors are deeply involved in the development of CCS and one author has been project management for the hospital test project central is the paper. The closeness is however seen at a time as a strength and a weakness as it provides detailed insight in the processes of the case. The third author has acted as critical external vis a vis these indepth insights.

\section{Review of the literature}

This selective literature review follows three steps: first some general considerations of innovation and standards, than review of studies of the relation innovation and standardisation and third the development of the five criteria.

\subsection{Innovation}

The conceptualisation of the role of innovation in development of companies, industries and societies has expanded from mostly focusing on product innovation and secondary process innovation [24] into focusing on a broad range of renewal, newness which is often claimed being far more important to company survival and prosperity [24]. This broader range of innovation encompasses financial innovation, Business model innovation, management and organisational innovation, technological and IT innovation, innovation in networks, alliances and communities [23], [25], service innovations and customer relations innovations, such as channels and brands [24, 26]. Also a lot of interest has been allocated to involving users in innovation [22, 23, 26]. This development complicates defining innovation and understanding how innovation impact on business development. OECD has elaborated the following definition:

"An innovation is the implementation of a new or significantly improved product (good or service), or process, a new marketing method, or a new organizational method in business practices, workplace organization or external relations.” [27].

This definition is used here in an embedded manner. Innovation processes and innovations and standards as viewed as sociomaterial, with social and material (technical) aspects closely interwoven [18, 28].

\subsection{Standardization}

A standard can be defined as a specific type of rule meant for common use (by many) [29]. This use would equally often be of voluntary character as sanctioned by some authority. Moreover in a sociomaterial perspective a standard is inseparable from the consensus creating processes needed to create, maintain and develop a standard and the body mandated to facilitate these processes [21]. This is actually also 
reflected in the International Standardisation Organisation's understanding of standardization (quoted from [29]):

"[a] document, established by consensus, and approved by a recognised body, that provides for common and repeated use, rules, guidelines, or characteristics for activities or their results, aimed at the achievement of the optimum degree of order in a given context"

Moreover in a sociomaterial view processes of arriving at common rules are negotiated and complex and standardization can occur in context where mandated bodies are not involves [30].

\subsection{Innovation and Standardization}

Early work on innovation and standardization [31, 32], often pointed at the constraints and dysfunctional effects of standardization, where later works overwhelmingly advocate standardization [33-35]. In these works most focus is implicitly on product or process innovation whereas the broader set of possible innovations is rarely treated. Moreover where improved interoperability has been shown to improve company performance, [36] others has measured the losses of poor interoperability in the building sector [9] both of which results add to this indirect effect that improved performance can have on innovation. Importantly the flexibility of standards would also impact on its enabling features vis a vis innovation [34]

Scholars working on mass customization and modularity in product design [37-38], point at first the gains involved in standardizing certain repeated elements of the product structure allowing the design to focus on the specific more customer oriented elements. Such a mass customization strategy fits well with large complex building projects like hospitals that standardized interfaces between subsystems involve. Second modularity of the product design is equally well suited. Again here most focus is on product standardization and secondary process standardization, even if [38] do mention some of the organizational and managerial implications of creating products through mass customization.

It should be noted that building information and its handling in projects tends to be highly volatile and hap hazard because of the large number of players, components and processes [21]. [9] investigates the losses related to poor interoperability amongst the AEC and real estate players.

As a perspective the possibilities of establishing markets beyond single (unique) products and even mass markets would also involve standards as enabler for such market innovation [41]. And such development might lead to the change of entire business models of the involved companies, i.e. to business model innovation [42]. Finally large scope standardizations would encompass sector wide innovation, i.e. systemic innovation [43]. 
Information Standards enabling or constraining Innovative Hospital Facilities? -A

Scandinavian case

However standardisation continues to involve barriers and pitfalls also in its involvement with innovation. [44] in their empirical study of standards in use, point at the danger of finitism - attempting to create standards covering all aspects of a domain, which risks "locking" the use processes and ultimately leading to non-use of standards because they indeed become perceived as barriers.

Summing up, standards impact on innovation in the following ways

1. Standardization of product and process elements and improved interoperability indirectly provides resources for innovation as the standardized elements require less resources $[34,35]$

2. Standardization can enable efficient repetition and the engineering of innovation for single customers, i.e. a mass customization strategy of product development, [3839]

3. Standardization stabilizes processes in a volatile project based environment [21]

4. Improved interoperability and interfaces between subsystems enable product innovation [40]

5. Standardization enables entry of products into larger markets [41]

Adding to this list but in a more secondary manner innovation in the business model in both the business services organizations [42] and in public organisation, similarly in management, in the financing of the building, such as PPP might also be relevant $[1,4,42,43]$.

\section{The hospital project}

The present hospital building activity in Denmark is substantial [4]. DNVGødstrup is nevertheless one of the largest hospital building projects in Denmark. 130.000 new square meters are designed, constructed and erected over a decade and from 2020 the hospital will be able to make 47.000 operations per year.

Between summer 2012 and autumn 2013, the first major test project of parts of CCS, namely room and building classification, was carried out in this hospital project. The first prototypes and testing activities were developed during the autumn. In this context, the building client became allied with six software suppliers. Together, their six systems cover parts of the information flow from early conceptual design of a building (one system), over detailed design (two CAD-systems and a BIM system), cost and budget calculation (one system), and space management (one system). According to the project manager, the systems are able to identify building components, classify them and sort them. This also involves data flows supported by the chain of the six systems:

"At [the hospital] we are now at classification of rooms and about to classify building components. The six participating IT companies can actually all, almost all, classify. We have made an internal demo of an information flow: [list of the six 
systems]. The programs are capable of doing that. With CCS we can classify, sort, identify. The programs are further than I thought" (project manager, Nov. 2012).

The classification standard was implemented in six IT systems constituting a common infrastructure and covering important parts of early conceptual design and detailed design.

The central advantage of using CCS is envisioned to be that it integrate the four elements of 1. Classification of building information, 2.property data of building components and rooms in the building, 3. information levels to control the design and further processes, and 4. rules for measuring building components (metrics). It is one common system for handling building information in contrast to a normally completely fragmented building design context. The DNV- project was the first test of these visions.

\subsection{Standardisation with indirect impact}

Implementation and use of standards in the building industry such as CCS implies that a more common terminology and structures are implemented, concerning products, processes and data exchange. This also enabling commencing bridging between the many different IT-solutions that are in use across the companies participating in the project teams and enables smooth communication between the IT systems. A common structuring of buildings by designers is to perceive it as composed in rooms for various purposes, which therefore is one area of classification in CCS. Moreover it is also a demand that the standards should allow new innovative solutions, giving users a tool rather than a strict and detailed coding, that might create barriers for "thinking outside" the given frames, a recurrent initiator of innovation.

To do so CCS is in principle shaped as a collection of terms and concepts that can be brought together in different ways within the code structure. Users have a large room for manoeuvre to specify products and processes at the lower levels in the classification, while CCS also maintains a precise coding structure for specification at the first three to four levels, enabling IT-interpretation of the specification and exchance of data between it-systems.

A classification system is traditionally defined as a hierarchy of classes, and thus the number of classes of components or processes is fixed in the system. E.g. the classification system OmniClass has 211 different classes for doors, and the distinction of the classes primary are based of the properties of doors [45]. By it OmniClass actually determines the number of classes of components, which may exist for the user using this classification system. It can be right a challenge find the right class among the numerous types of classes or even to find a class which is adequate for a new innovative designed door component.

In contrast to traditional hierarchical classification systems like OmniClass, CCS has only one class for all types of door components. But CCS also allows you to add CCS-properties to the class (as many as you wish or need) thus you actually defined your own class-specification for your doors. CCS classification combined with CCS properties gives the users nearly an infinite numbers of combination possibilities to 
specify exactly the classes of building components needed. A well-defined syntax for code structure for specifying the created classes, act as a digital syntax for digital communication and exchange of the specification of the class.

The flexibility of CCS supports the users to be able to classify new solutions and at the same time be sure of, that the CCS code structure ensures that IT systems are able to interpret the specification og the class. Thus the implementation and the use of CCS indirect release resource from digital implementation to innovate.

The consultant unit of the hospital used CCS first to program rooms and later to organise building components preparing tendering documents. The room programming became more structured because all standard and special rooms entered the same structure enabling a move towards more standard rooms. Thereby the room programming became more efficient than usual for such large and complex building, here handling about 4000 rooms, whereof $80 \%$ became classified as standard rooms. This indirectly created resources for the design of the remaining unique rooms. Here the envisaged flexibility of CCS was used and evaluated instrumental. The combination of the classification tables and codes worked. Property data however were not readily available and the design team therefore developed their own properties to enter in the CCS structure.

The client evaluates that better structured building component data has given considerable positive effects in the tendering of contractor contracts, where the design team of engineering and architects are enabled in several ways.

\section{2 Standardization supporting a mass customization platform}

CCS is a structure for a digital platform for the building product and supports the notion of a product master [38]. The database-embedded product master, as the CCS server, supports the generic product properties and structures as well as the specific.

The hospital project involves a large amount of repeated components, building elements up to entire blocks of beds. The engineering and architectural design group work with room programming using CCS reduced the number of special rooms and increased the standard room to $80 \%$ of the 4000 rooms. The design of the last $20 \%$ that could not be standardized as they were unique special rooms. This reveals using mass customisation strategies with CCS for example design, function and equipment such as doors, windows, and HVAC equipment (and for example oxygen) has become more efficient than usual for such large and complex building.

The document analysis of the developed standards supported that the CCS standard might be offering too little depth in the fixed structure and too much flexibility for local appropriation. Such a partition runs counter to obtaining efficiency through the repetition of the core/product master [38, 39]. Some of the building consultants involved in the hospital project expressed similar concerns.

\section{3. Standardisation stabilises building processes}

It is considerably easier to develop new innovative digital solutions in the building industry, i.e. the building processes from conceptual design, detailed design, 
production and operation, when your work platform is based on a well-known and stable production environment. A production environment which does not set any technical limitation, but supports the creation of new innovative solutions, is also more or less a necessity for a creative result.

To create a stable production environment, you need to stand on a standardised digital platform, where well-defined and structured building terms are implemented and where simple data operations, like data creation, search, sorting, exchange, can be executed seamless without any IT-specified knowledge for the users.

The purpose of CCS is to create a standard digital platform for the building industry, on which the different parties are able to create a stable digital productions environments. An environment from which they can create new innovative solutions for their building projects, whiteout worrying about whether the solutions can enter into a digital structure or can be communicated and be interpreted digital by other parties' it-systems.

To ensure a stable digital production environment you need to implement the CCS standard platform in your working methods and IT-systems, and surely also upgrade your employees competences in how the this new platform are able to support them in producing new innovative solution based on the ever ongoing demands for new solutions and progress.

At the hospital project CCS has first supported a systematic detailed planning of the design process, digital architecture and work method. This planning created stability as it afterwards had to be followed strictly. Moreover and second CCS supported "data discipline" in all the sub activities. Also the enabled reuse of the CCS elements supported stabilisation. An important prerequisite for this was a systematic training effort of the members of the design team, especially those involved with Building Information Modelling (BIM).

\subsection{Product development enabled by interoperability and interfaces}

Interoperability and interfaces within the product structure is an organised way to enable a number for players to contribute to product innovation through digital design collaboration and communication. In a somewhat similar vein as the well known apple i-phone platform, the CCS platform provides extensive space for supplementary, enlarging innovations "as long" as they comply with the platform they can be taken onboard.

At the hospital project, CCS, enables handling of many types of digital objects, such as documents, BIMs, spreadsheets, data sets (in databases) and drawings. The classification codes enable automatic identification by distinguishing between the items. It is common in large complex buildings project to use considerable resources for coordination of the design activities, which is located in the many participating companies at numerous places and usually involving many different IT -systems and data structuring approaches. Here CCS supports interoperability also by standardising the interfaces between these systems. 


\subsection{Standardisation opens larger markets for products}

Standardisation of design, production and operation processes is enabled by use of BIM. Process innovation through reuse and iterations are important new opportunities: Reuse of parts of the sustainable design is enabled by well-structured data ordered as objects and more feasible if one encounter a (larger) Nordic market and markets beyond that. Several building consultants involved in the test project have won new project in the health care sector.

IT suppliers participating in the hospital project have used their experiences with CCS to incorporate the classification in their IT-systems. They are currently marketing that in the Nordic and Baltic region. More in general there is a large global market for hospital design providers, where experiences of CCS can be transformed into design service offerings globally. Here it is likely however that competing standards will be part and parcel of the future market conditions [10, 11, 42].

\section{Discussion}

In the following the five innovation -standard relation types is first discussed, also looking at enablers and barriers within each dimension. Then an overall discussion is summing up the results.

The First dimension is the indirect enabling. The standardisation is expected to indirectly provide resources for innovation. The case shows how standardisation in the tendering process prepares for cost reductions that indirectly can provide more space for innovative solutions developed in the products. The client thus claims to have saved 2, 68 mill. Euro in this way [14]. The communicated tendering material is easier to access, better structured, and more homogenous, which in turn generate more comparable and cost efficient tenders. However the implementation and co-testing of the standards with the development organisation also required substantial investment in terms of hours and human resources. One issue being that the testing of the standard commenced before the standard was fully developed, i.e. a beta version was provided in the beginning and later improved.

Second standardisation can promote efficient repetition and the engineering of innovation for single customers (i.e. a mass customisation). The room programming and the standardisation of it gave considerable result enabling innovation both on the standard side and the customer specific side. Also here it required considerable implementation work to reach this result in the test project.

Third standardisation is expected to stabilize processes. In the hospital project this occurred as improved planning and also a relatively strict practice of following these plans providing stabilisation. It was carried out in a manner that demanded systematic change management, provided through training.

Fourth an improved interoperability and interfaces between subsystems enable product innovation. The classification enabled handling of many types of digital objects, and supported interoperability also by standardising the interfaces between these involved systems. 
Fifth standardisation is expected to create larger markets for products, which in the hospital project both occurred as marketing of new solution and a still unexploited potential for offering new services. The IT-suppliers were provided with competences after having developed relevant IT-tools, which enable them diffusing the standard. More specifically the public building client evaluates that better structured data on building component give considerable positive effect in the tendering of contractor contracts, where the design team of engineering and architects are enabled i several ways by the computerized information standard.

As the standard CCS at present has only been tested in Denmark its diffusion will face technical and social barriers. Technically CCS would have to coexist with a range of other building information standards [11], and the interface to these other standards in Scandinavia and beyond are important rather than imagining that CCS would creatively destruct the other standards by technical superiousity. As noted by $[12,13]$ multiple standards in domains are a likely future scenario. Importantly the standards in use in a Scandinavian setting are overlapping and partially mutually compliant [47]. CCS builds on the international ISO standard 13006-2, which broadly specifies a systems model of buildings processes organising them as resources as input to a process (transformation) that lead to a result and that are feeded with properties of the involved components and entities. This and other commonalities do not overcome the technical differences which are also coupled to social aspects such as the organisation of influence on the further development of standard. It has previously been seen and it is likely that the trajectory of CCS will involve a hybridization of the standard, i. e. a mixing of content, with other Scandinavian standards [48].

The range of possible future innovation involves financial, organisational and managerial innovations as well as community innovation once the hospital is built [4, 23]. Importantly the IT supported operation of the built facilities would be enabled by a comprehensive "As-built" building information model. It would be a possibility to do space management, technical maintenance, reconfiguring of the use and more in the continual further development of the hospital facilities.

The analysis shows that effects of standards impacts on a series of players in the industry and the effects for each party are often counter to each other. The effect are not intraorganisatoric with classification of rooms enables designers overview of the complex building. But the interorganisational effects are very import as when room programming is carried out in interaction with client representatives as well as other designers. Evaluating the impact of standards in test projects can be questionized. Especially during test projects there is a risk that some parties experience they carry out unpaid work for other parties. The test project experiences could be seen as "childrens diseases", but it should be noted that even if most would think of standards as stable and even rigid, thereby viewing an implementation as a short barrier to overcome before a long stability, this is hardly the contemporary case. A series of dynamics would imply that the standard would be under continual development, related to adoption in and between organisations, related to technological development of building materials and methods, related to the promotion, revision 
Information Standards enabling or constraining Innovative Hospital Facilities? -A

and distribution and related to the rapport with or integration into public regulation [29]. Therefore swift implementation would be a demand for a contemporary standard as would the flexibility to adapt to context and change.

\section{Conclusion}

The impact of building information standards on innovation is both inter- and intraorganisational, contradictory and dynamic. In our case there are two main indirect enablers of innovation; first the building client claims to have saved money, and second the IT-suppliers and design companies appear to have been provided with competences. But a range of other effects occur as well: The public building client evaluates that better structured data on building component give considerable positive effect in the tendering of contractor contracts, where the design team of engineering and architects are enabled in several ways by the computerized information standard. The standardized building information appear to provide cost reduction and stabilised processes that indirectly opens for innovation, but also that the standardisation of rooms led to more direct innovation in the design of rooms both in the standardised and in the unique rooms, in line with a mass customisation strategy. Moreover the use of one common standard enables a far better coordination than previously inside a hospital project like this one, even if the broader and longer term perspective probably involves handling more standards over time and place and or a increasing hybridisation of standard, that they would tend to overlap and with some common structures and components. Finally we currently witness IT-suppliers using their experience with classification in providing new solutions and marketing these on a Nordic market, whereas we still have to see the event of the design companies following the same path of providing new services related to improved classification.

\section{References}

1. WHO. Investing in hospitals of the future. World Health Organization. Copenhagen. 2009

2. OECD: Sweden 2013 Raising Standards. OECD Reviews of Health Care Quality.OECD. 2013

3. Hågøy T. Nye helsebygg for 73 milliarder på 10 år. Dagensmedisin. Downloaded from http://www.dagensmedisin.no. 2013.

4. Danske Regioner. Nye sygehusbyggerier: Det erhvervsmæssige potentiale. Danske Regioner. København. 2011.

5. STD: Sector Review The Consulting Engineering and Architectural Groups. A Swedish and International survey. The Swedish Federation of Consulting Engineers and Architects (STD). Stockholm. 2012.

6. Bernstein, H.M.: The Business Value of BIM in Europe. McGraw-Hill, Bedford. 2010

7. Bernstein, H.M.: The Business Value of BIM in North America. McGraw-Hill, Bedford. 2012.

8. Eastman C., Teicholz P., Sacks R. and Liston K. BIM Handbook: A Guide to Building Information Modeling for Owners, Managers, Designers, Engineers and Contractors. 2nd Ed. Wiley \& Sons. Hoboken. 2011. 
9. Gallaher M.P., O’Connor A.C., Dettbarn Jr. J.L.,, and Gilday L.T. Cost Analysis of Inadequate Interoperability in the U.S. Capital Facilities Industry. National Institute of Standards and Technology. Gaithersburg. Maryland. 2004

10. Laakso M, Kiviniemi A.: The IFC Standard - A Review of History, Development, and Standardization. Journal of Information Technology in Construction. Vol 17, pp 134-161. 2012.

11. Cuneco: Website in English of cuneco, the Danish center for classification and productivity in construction. Accessed January 2014.

12. Berman D. Make It What Way? The Impact of Multiple Standards Regimes. Int. Jrnl. of Soc. of Agr. \& Food, Vol. 20, No. 1, pp. 69-89. 2013.

13. Reinecke J, Manning S. and von Hagen O. The Emergence of a Standards Market: Multiplicity of Sustainability Standards in the Global Coffee Industry. Organization Studies33(5-6) 791-814. 2012

14. Andersen, U.: Digitale tilbudslister sparer Gødstrup Sygehus for mindst 20 mio. kroner. Ingeniøren. 6 september. 2013.

15. EU: Directive 2012/27/EU on energy efficiency. The European Parliament and of the Council. Bruxelles. 2012.

16. Walsham G.: Interpreting Information Systems in Organizations. Wiley, Chichester. 1993

17. Bryman A, Bell E. Business Research Methods . 3rd Ed. Oxford University Press. Oxford. 2011.

18. Orlikowski, W. J. \& Scott, S. V.: 'Sociomateriality: Challenging the separation of technology, work and organization', Annals of the Academy of Management, 2, pp. 433474. 2008.

19. Webster, J. and R. T. Watson. Analyzing the past to prepare for the future: Writing a literature review" in MIS Quarterly Vol. 26, No. 2. 13-23. 2002.

20. Greenhalgh T., R. Peacock. Effectiveness and Efficiency of Search Methods in Systematic Reviews of Complex Evidence: Audit of Primary Sources. British Journal of Medicine.331(7524): 1064-1065. 2005

21. Koch C. and Jacobsen K. Computerized Information Standards Enabling Innovation in Public Procurement of buildings. Proceedings Human Computer Interaction 22 - 27 June 2014, Creta Maris, Heraklion, Crete, Greece. 2014

22. Koch, C. and Chan, P.: Projecting an Infrastructure - Shaping a community. In Carrillo P. and Chinowsky P. (eds): Proceedings EPOC 2013 Conference. Engineering Project Organization Society, Colorado. 2013.

23. Botero, A., Vihavainen, S., Karhu, K.: From closed to open to what?: an exploration on community innovation principles. Proceedings of the 13th International MindTrek Conference: Everyday Life in the Ubiquitous Era. 2009.

24. Fagerberg J, Mowery D.C., Nelson R.R.: The Oxford Handbook of Innovations. Oxford University Press, Oxford. 2004.

25. Koch, C.: Innovation networking between stability and political dynamics. Technovation. Vol. 24, 9, pp. $729-739.2004$.

26. Chang, T-R., Kaasinen, E.: Three user-driven innovation methods for co-creating cloud services. INTERACT'11: Proceedings of the 13th IFIP TC 13 international conference on Human-computer interaction, Volume IV. 2011.

27. OECD: Oslo Manual, Guidelines for collecting and interpreting innovation data. 3rd edition. OECD Publishing, Paris. 2005.

28. Timmermans S. and Epstein S.: A World of Standards but not a Standard World: Toward a Sociology of Standards and Standardization. Annual Review of Sociology Vol. 36, pp. 6989. 2010. 
Information Standards enabling or constraining Innovative Hospital Facilities? -A

29. Brunsson N., Rasche A. and Seidl D. 2012.The Dynamics of Standardization: Three Perspectives on Standards in Organization. Organization Studies 33(5-6) 613- 632.2012.

30. Hanseth, O., Jacucci, E., Grisot, M., and Aanestad, M. Reflexive Standardization: Side Effects and Complexity in Standard Making. MIS Quarterly, vol. 30, no. 2, pp. 563-581. 2006

31. Farrell $\mathrm{J}$ and Saloner G.: Standardization, Compatibility, and Innovation. The RAND Journal of Economics, Vol. 16, No. 1, pp. 70-83. 1985.

32. Kahan, M. and Klaussner, M.: Standardization and Innovation in Corporate Contracting (Or "The Economics of Boilerplate"). Virginia law review. vol:83 iss:4 pg:713 -770. 1997.

33. Ekholm, A., Blom, H., Eckerberg, K, Löwnertz, K., and Tarandi, V.: BIM Standardiseringsbehov. Svenska Byggbranschens Utvecklingsfond, Stockholm. 2013.

34. Lillrank P.: The Quality of Standard, Routine and Nonroutine Processes.Organization Studies, Vol 24 no 2, Pp 215-233. 2003.

35. Sandholtz, K.: Making Standards Stick: A Theory of Coupled vs. Decoupled Compliance. Organization Studies. Vol 33, no 5-6, 655-679. 2012.'

36. Zhao K and Xia M. Forming Interoperability Through Interorganizational Systems Standards. Journal of Management Information Systems, Vol. 30, No. 4, pp. 269-298. 2014.

37. Hanseth O., Nielsen P. Infrastructural Innovation: Flexibility, Generativity and the Mobile Internet. International Journal of IT Standards and Standardization Research (IJITSR) 11(1), 27-45. 2013.

38. Piller, F.T. and Tseng, M.M.(eds): Handbook of Research in Mass Customisation and Personalization World Scientific New Jersey. 2010.

39. Poorang A., Piroozfar E., Piller F.T..Mass Customisation and Personalisation in Architecture and Construction. London, Routledge 2013.

40. Clark, K.B. and Baldwin, C.Y.: Design Rules. Vol. 1: The Power of Modularity: MIT Press, Cambridge, Massachusetts. 2000.

41. Schilling, M.: Strategic Management of Technological Innovation, McGraw-Hill, New York. 2008

42. Teece D.J. Business Models, Business Strategy and Innovation. Long Range Planning Volume 43, Issues 2-3 Pages 172-194. 2010.

43. Malerba, F. Sectoral systems of innovation: concepts, issues and analyses of six major sectors in Europe, Cambridge University Press 2004

44. Bowker G.C. and Star, S.L: Sorting Things Out: Classification and Its Consequences.: MIT Press, Cambridge, MA. 1999

45. Omniclass: Omniclass website, accessed at http://www.omniclass.org/ January 2014.

46. Fomin, V.V.: Standards as Hybrids: An Essay on Tensions and Juxtapositions in Contemporary Standardization International Journal of IT Standards and Standardization Research, 10(2), 59-68, July-December 2012.

47. Ekholm L., Häggström Mappning mellan systemen för byggklassifikation BSAB 96 och DBK Lund University. Lund 2011.

48. Shen X, Graham I., Stewart J., Williams R. Standards Development as Hybridization. International Journal of IT Standards and Standardization Research (IJITSR) 11, 2, pp 3445. 2013. 